\title{
Abnormal Lymphocyte
}

National Cancer Institute

\section{Source}

National Cancer Institute. Abnormal Lymphocyte. NCI Thesaurus. Code C36725.

A lymphocyte characterized by a structural or functional abnormality. 